\title{
BMJ Open Financial, opportunity and psychosocial costs of spinal muscular atrophy: an exploratory qualitative analysis of Australian carer perspectives
}

Michelle A Farrar, ${ }^{1}$ Kate A Carey, ${ }^{1}$ Sarah-Grace Paguinto, ${ }^{1}$ Georgina Chambers, ${ }^{1,2}$ Nadine A Kasparian ${ }^{1,3}$

To cite: Farrar MA, Carey KA, Paguinto S-G, et al. Financial, opportunity and psychosocial costs of spinal muscular atrophy: an exploratory qualitative analysis of Australian carer perspectives. BMJ Open 2018;8:e020907. doi:10.1136/ bmjopen-2017-020907

- Prepublication history for this paper is available online. To view these files, please visit the journal online (http://dx.doi. org/10.1136/bmjopen-2017020907).

Received 1 December 2017 Revised 27 April 2018 Accepted 4 May 2018

\section{Check for updates}

${ }^{1}$ Discipline of Paediatrics, School of Women's and Children's Health, UNSW Medicine, Sydney, New South Wales, Australia ${ }^{2}$ National Perinatal Epidemiology and Statistics Unit, Centre for Big Data Research in Health UNSW, Sydney, New South Wales, Australia

${ }^{3}$ Heart Centre for Children, The Sydney Children's Hospitals Network (Westmead and Randwick), Sydney, New South Wales, Australia

Correspondence to

Dr Michelle A Farrar;

m.farrar@unsw.edu.au

\section{ABSTRACT}

Objectives Spinal muscular atrophy (SMA) has profound implications for patients and families. The aim of the present study was to gain insights into the effects caring for a child with SMA has on the costs incurred by families caring for a child with SMA from carer perspectives to identify gaps in provision of care, inform public policy and cost-effectiveness analyses.

Design Interpretive phenomenological analysis guided the delivery and analysis of semi-structured interviews undertaken to explore the financial, opportunity and psychosocial costs associated with caring for children with SMA.

Participants and setting Parents of children with SMA types II and III from a single Australian paediatric neuromuscular clinic participated in this study. Results A range of experiences were reported and information saturation $(n=7)$ was reached endorsing themes, including: significant financial and caregiving burdens, adjusted career choices and limitations on career progression and a complex landscape of access to funding, equipment, support and resources. Opportunity costs of foregone employment, purchases and leisure activities were substantial, as were emotional and social impacts. Participants voiced determination and resilience, and called for continued efforts to improve supportive care services and resources.

Conclusions The range and nature of costs met by families caring for a child with SMA were found to be expansive and not typically recognised. These include high direct costs associated with goods and services, indirect costs associated with voluntary care, substantial and long-term opportunities foregone in paid employment and career progression and unmeasured or hidden costs associated with mental health burden.

\section{BACKGROUND}

Spinal muscular atrophy (SMA) is a hereditary neurodegenerative disease that typically leads to severe physical disability and has profound implications for the health and well-being of patients and their families. Phenotypes are based on motor milestones achieved and age of onset; SMA type I has

\section{Strengths and limitations of this study}

- This qualitative study provides an in-depth account of the range and nature of costs incurred by families caring for a child with spinal muscular atrophy (SMA) and has identified costs not previously described or under-reported by quantitative studies.

- The present study complements recent quantitative studies that have examined the total costs of care for patients with SMA and helps to provide a more comprehensive picture of the overall burden of SMA.

- Further studies assessing male relatives, who were not the primary carers in the present cohort, and patients with SMA type I will extend understanding.

- Findings from the present study, together with quantitative studies, may be used to inform the development of measures or tools to better capture economic burden in this setting.

onset before 6 months, infants are unable to sit independently and survival is limited. ${ }^{1}$ In SMA type II, weakness is evident between 6 and 18 months and affected individuals are able to sit but not walk independently. SMA type III has onset after 18 months and independent walking is achieved, although may not be maintained.

Advances in supportive care and equipment have improved patient survival and quality of life; however, the substantial cost of these services has increased the financial burden on families and the healthcare system. ${ }^{2-5}$ The cost of SMA in the USA and Germany has been estimated at US $\$ 957$ million and $€ 106.2$ million per year, respectively. ${ }^{6}$ In Spain, the direct non-healthcare costs of SMA were higher than direct healthcare costs and associated with reduced caregiver quality of life. ${ }^{8}$ This was predominantly related to informal caregiving, highlighting the importance of counting significant hidden or unmeasured costs. Caring for a child with SMA can entail 
significant financial costs associated with family caregiving, employment constraints, carer burden, social limitations and reduced carer well-being, all of which are typically not recognised in the literature in quantitative studies.

Several qualitative studies have provided varying perspectives of the reality and quality of life for patients and carers living with SMA, which may be dependent on individual lived experiences, SMA type and level of appropriate resources. ${ }^{9-11}$ Understanding the range and extent of unmeasured costs incurred by families caring for a child with SMA is important for identifying gaps in the provision of care, informing cost-effectiveness analyses and providing a comprehensive account of the economic burden of disease. Such information is timely, with the first regulatory approval of nusinersen for the treatment of SMA and the likely transformation of treatment options over the next few years, to be able to make a case for new therapies and to evaluate their impact. ${ }^{12-16}$

The aim of this qualitative study was to gain insights into the effect caring for a child with SMA has on financial (both direct and indirect), opportunity and psychosocial costs associated with SMA care from a primary carer perspective within the Australian health system. In the context of this study, direct costs were defined as those associated with fiscal transactions, such as the purchasing of goods and services, indirect costs were defined as unpaid care provided by the primary carer, family and volunteers and opportunity costs as career prospects and social experiences foregone by the primary carer and their family.

\section{METHODS}

An interview guide with a carefully designed set of questions was used to explore a range of topics that elicited direct, indirect, opportunity and psychosocial costs associated with SMA from primary carers' perspectives. The wording and sequencing of questions was left open to support wider discussion and guided by participant responses. Primary carers of children with genetically confirmed 5qSMA types II and III managed at the Sydney Children's Hospital multidisciplinary neuromuscular clinic, Australia were invited to take part in this qualitative study. Participants were eligible for study participation provided they had sufficient English language skills to take part without the aid of an interpreter. Eligible individuals were sent a letter of invitation from their treating clinician, with a study information sheet, consent form, questionnaire and reply-paid envelope. Individuals who opted into the study by returning the correspondence were then contacted to arrange a telephone interview by one of the investigators. All participants gave written informed consent. Participants were informed of the study aims, assured that their responses would not affect their clinical care and they could withdraw at any time. Participants were informed that a letter with results would be sent at the conclusion of the study.
Each interview was conducted by the second author and lasted between 15 and $30 \mathrm{~min}$. Interviews were conducted between May and June 2016, prior to regulatory approval of nusinersen. The semi-structured individual telephone interviews were recorded and transcribed verbatim. Demographic data collected included carer age, employment status, occupation, household income, residential location (urban or rural), child's SMA severity and time spent caring.

\section{Patient and public involvement}

The study team's clinical experience with and feedback from the patients and their families provided the inspiration for and informed the design of the study. The interview guide was further refined by feedback provided by the participants. Parents and carers of patients were recruited to participate in the interviews, but were not directly involved in the recruitment or conduct of the study. Participants were provided with a summary of the study findings.

\section{Data analysis}

The conceptual framework of Miles et al was used to analyse interview transcripts in four phases. ${ }^{17}$ Initially, all authors independently read transcripts, annotating reflections on salient content. Next, a set of agreed themes were generated. Subsequently, a narrative summary of each interview was developed identifying overall themes, and these themes were further discussed and interpreted by the group. This iterative process was repeated until all transcripts had been interpreted. Finally, the salient findings across all interviews were represented by a set of descriptive and interpretive themes. These were synthesised and overarching themes were developed and critically appraised. Descriptive statistics were used to assess demographic and clinical characteristics of the sample.

\section{RESULTS}

\section{Demographics and clinical characteristics}

The sample comprised seven primary carers of eight children with SMA types II and III, yielding a response rate of $80 \%$ (table 1). Male carers were also invited to participate in the study; however, no responses were received. All carers were married, aged between $30-39$ years $(4 / 7)$ and $40-49$ years $(3 / 7)$, and the average age of their children with SMA was 6.4 years (table 1 ).

\section{Financial costs}

All participants recognised significant increased demands and stresses on family finances, related to the direct costs of caring for a child with SMA. Appropriate housing was identified as the largest financial cost faced by families and $3 / 7$ reported these costs as prohibitive to the attainment of wheelchair accessible housing. All but one carer described significant costs associated with the purchase of medical, seating and mobility equipment, vehicle purchase and wheelchair accessible modifications and specialised 
Table 1 Demographic characteristics of the sample $(n=7)$

\begin{tabular}{ll}
\hline Characteristics & $\mathbf{n}$ \\
\hline Mothers & \\
Age (years) & \\
$30-39$ & 3 \\
$40-49$ & 6 \\
In paid employment & 22.2 \\
Mean hours worked per week & (range 12-25) \\
& \\
Gross annual household & \\
income (US\$) & 1 \\
$<25000$ & 0 \\
$25000-50000$ & 2 \\
$51000-100000$ & 4 \\
$101000-150000$ & 0 \\
$>150000$ &
\end{tabular}

Hours spent caring for child with SMA per day

\begin{tabular}{|c|c|}
\hline $0-4$ & 3 \\
\hline $4-8$ & 2 \\
\hline $8-16$ & 1 \\
\hline $16-24$ & 1 \\
\hline \multicolumn{2}{|l|}{ Children* } \\
\hline Mean age (years) & $\begin{array}{l}6.4 \\
\text { (range 1.6-14.1) }\end{array}$ \\
\hline \multicolumn{2}{|l|}{ SMA type } \\
\hline II & 5 \\
\hline III & 3 \\
\hline \multicolumn{2}{|l|}{ Current best function } \\
\hline Able to sit & 4 \\
\hline Able to walk & 2 \\
\hline Unable to sit or walk & 2 \\
\hline
\end{tabular}

${ }^{*} \mathrm{n}=8$ as one mother in the study has two children diagnosed with SMA type III.

SMA, spinal muscular atrophy.

bedding. Numerous paramedical costs, including continence products, therapies, vitamins and enteral formulas were identified by $6 / 7$ families. See table 2 for illustrative quotes for each thematic area identified.

The importance of additional financial resources to meet increased demands was acknowledged by $3 / 7$ participants. Some mothers described their need to return to work earlier than planned to help pay for their child's equipment. In other families, the father increased his work hours, often impacting time together as a family. Additional financial resources included assistance from family, fundraising and community or charity donations, and accessing superannuation to the detriment of financial provisions for retirement.

With increased financial demands resources were redirected, with $4 / 7$ families reporting loss of disposable income to fund healthcare, equipment and modifications rather than leisure activities. Spontaneous expenses were replaced with strict budgeting. Mothers often talked about the lack of capacity to afford the equipment they would like for their child. Additional solutions included 'do it yourself', delaying or carrying out the least possible modifications in 5/7 families, or relinquishing other opportunities or objects. Four parents described balancing the costs associated with their child's care against lost opportunities for meeting the needs and wants of other family members. Parents viewed each of their children as individuals with different needs and costs, and were conscious of the impacts for siblings. For example, weighing the costs associated with siblings' sports activities, against the costs of care needed for their child with SMA.

In fulfilling the demands of caring, the importance of support from their partner and their own parents was highlighted, with the concern that ageing and reduced physical capacity of grandparents meant this was not a long-term option. Barriers to alternative caring options included difficulty accessing appropriate respite services, and anxieties about non-family members tending to their child's needs. Carer options that allowed parents a reprieve were often limited to close family members and parents expressed a sense of pride in being able to take care of their child: "our care keeps our child out of hospital" (P006).

\section{Opportunity costs}

Lost income from limited employment and career opportunities Caring had a negative effect on labour force participation; $6 / 7$ mothers described reducing or relinquishing paid work due to increased demands of caregiving. Several carers described significant opportunity costs associated with foregoing work aspirations and career progression for less demanding, lower paid roles with greater flexibility: "I have the potential to probably take a management position but I don't" (P006). Reduced career opportunities were perceived as having financial consequences, and consequences for carers' well-being and sense of self. One mother noted, "I hate it, but it pays the bills and that's what I need to do and it gives me flexibility" (P008). A reoccurring theme for all participants was the substantial indirect costs of care, particularly the role of family in informal care, with assistance of grandparents mentioned by most $(5 / 7)$ as critical in enabling mothers to participate in the labour force.

\section{Physical, mental and emotional health costs}

\section{Caring with little or no reprieve}

Mothers described the all-consuming nature of caring for a child with SMA and the impact of this on the family. Caring was perceived as 'never ending', generating time expenditure and fatigue. Some mothers described their caring role as ' 24 hours a day', including repositioning their child at night, and never leaving their child's side. While for others, their identity as a parent was replaced with that of being a carer "in a way I feel more like a carer rather than a mum" (P008). 
Table 2 Thematic areas and illustrative quotes

Thematic area Illustrative quotes

Financial costs

Increased expenses

"We didn't think it would be this expensive and the equipment wise they're so dear, like I said the power chair on its own's around \$30,000". (P005, SMA type II)

"We're going to have to purchase the vehicle, plus the modifications for the vehicle. So depending which way we go there it can be, apparently around \$75,000 depending on what vehicle you get and what mods you choose". (P008, SMA type II)

Reduced income $\quad$ "I would like to work more but I can't because I obviously have to be there for him in terms of his care". (P010, SMA type II)

"I had a like a managerial position and then after having [my son] have pretty much not progressed at all. And even now I just... I have the potential to probably take a management position but I don't, I take a, just an assistant position". (P009, SMA type III)

Redirecting resources and living without

"Well I guess, you know, 'cause my other son is into sports so, financially we support him doing that and 'cause [my son] can't do that, and the stuff that we spend our money on is for his care". (P006, SMA type II)

"Oh well, it places a lot, yeah it placed quite a financial burden on our family in terms of you know just having to live without". (P009, SMA type III)

\section{Opportunity costs}

Time spent caring

"Umm, so that includes, you know, personal care and then um medical as required, like he's PEG fed and he's got a BiPap and yeah, pressure care and things like that, physio, stretching. Um... so yeah we're his... basically full time carers, myself and my husband". (P006, SMA type II) "You've always got to be there just in case". (P007, SMA type II)

Time spent organising and waiting for equipment "Like she was diagnosed two and a half years ago and her wheelchair situation still hasn't been sorted properly". (P001, SMA type III)

"Like at the moment I made two enquiries [for respite] and I'm still waiting for them to get back to me and that was a couple of months ago". (P006, SMA type II)

Employment and career "I was actually quite career driven and everything um and that was a massive shock to the system progression when we got told her diagnosis because it just basically means I'm never...I can never go back to work full time, I can never BE THAT again". (P008, SMA type II)

"Um pretty much, [be] cause I only work 2 days a week. I suppose I'm... not been overlooked but, like you're only a part-timer, there's not much career progression in terms of that". (P010, SMA type II)

Information, funding and support needs

Support from health 'Well the children's hospital have been excellent'. (P010, SMA type II) system

"Um it's actually been really positive...Um, my OT and my physio and, like all the guys at the Sydney Children's Hospital and stuff are just phenomenal". (P008, SMA type II)

Limitations to financial "So...just little things like that make a... a really shitty situation so much harder. Like you've been support dealt this horrible news and it does feel like a lot of the time you've got to fill out a crazy amount of forms, and beg, borrow and steal to try and qualify for any sort of help sometimes". (P008, SMA type II)

Lack of knowledge and "Um, I think one thing is, is you don't know what's available". (P007, SMA type II)

awareness of available resources

"So I feel like there's been lots of support for us personally as parents but not in the case of, 'talk to these people', 'ask for this funding', 'you need these pieces of equipment' ". (P008, SMA type II)

\section{Physical, mental and emotional health costs}

Changes to family dynamics and relationships
"Um we can't do a lot of family things together anymore". (P007, SMA type II)

"I mean yeah it's probably affected our, my relationship with my partner. Um because yeah, we don't get a lot of that time out I guess. But I think that's kind of just expected with having a child with special needs I think". (P009, SMA type III)

"It takes a toll on the whole family... we just continuously worry about him". (P010, SMA type II) "In a way I feel more like a carer rather than a mum...I do more stuff with her relating to caring". (P008, SMA type II) 


\section{Table 2 Continued}

\begin{tabular}{ll}
\hline Thematic area & Illustrative quotes \\
\hline Carer well-being & "It's probably made me stressful. Cause usually I'm pretty casual and um happy and I feel quite... \\
um... yeah just stressed, stressed, I don't know". (P009, SMA type III) \\
"Um, and my poor husband, his back... he like, cause he's at that age he's asking 'can I walk, can I \\
walk', hubby will just grab him and move him around the house for an hour so he's acting like he's \\
walking". (P005, SMA type II) \\
"Um, I suppose there's an emotional cost. I'm always worried about him. I stress about like if he's \\
ok and all sort of stuff". (P010, SMA type II) \\
"But I also find like with the play dates or anything, everyone's got to come to our house, we can't \\
go anywhere. So she doesn't get to go anywhere else with other parents". (P007, SMA type II) \\
"Um, you know, probably, like travel. Going away, being able to, yeah. Like for us to go away is... \\
is hard because we have to look at all the logistics, and carting equipment, and [my son's] health \\
and, yep, so we haven't got that freedom". (P006, SMA type II)
\end{tabular}

Caring was also described as having an impact on the physical and mental well-being of carers. Mental fatigue, stress and back pain due to lifting was mentioned by most participants, and carers often spoke of prioritising their child's needs ahead of their own care. The emotional burden for all participants was clear and included concerns about the future health of their child; "there's an emotional cost... it takes a toll on the whole family...we just continuously worry about him" (P010). Participants worried intensely about future fiscal costs and many described finding it difficult to imagine the future. Most carers' hopes related more to the health of their child than being aspirational, while others expressed an inability to have hope. There was also an emotional toll to contending with waiting lists for services and equipment and 'trying to get (these) right'.

Common throughout parents' narratives was the challenges in pursuing leisure activities, with consequences for the family's broader experiences and opportunities for social interaction. While financial costs were identified as an issue for some $(3 / 7)$, difficulties in this domain were more frequently described in terms of practical burdens associated with leisure activities. Lack of accessibility was considered prohibitive to participating in many leisure experiences: "I wouldn't say the financial costs for us is as big a thing as the wheelchair not being able to go places...it affects the family more" (P007). The child's medical needs, functional dependence and wheelchair access was associated with a loss of spontaneity in daily life. Consequently, almost all participants described a narrowing of social networks. The costs and practicalities of care also often divided the family unit, with attempts to ensure other siblings did not 'miss out' (P007). The carer role was perceived by some as changing the dynamics of the marital relationship as well: "I don't feel like my partner and I have much of a relationship anymore...we don't get a lot of that time out" (P008).

\section{Information, funding and support needs}

A complex landscape of access to information, funding, equipment and resources was described by all carers, who spent a substantial amount of time and effort navigating the system and trying to get 'the right' solutions for their child. Mothers described available funding schemes as 'confusing' and efforts required to secure funding were also highlighted; "a lot of the time you've got to fill out a crazy amount of forms and beg, borrow and steal to try and qualify for any sort of help" (P008). Government financial assistance was described as only partially covering the costs of essential equipment and modifications $(4 / 7)$, and in most cases $(5 / 7)$ families were reliant on support from charities and fundraising to cover financial gaps. For those receiving a government carer allowance, the amount received was considered a pittance compared with the actual costs of caring. Several participants identified the lack of a clearly defined, integrated support pathway: "I don't think anyone sits down and says, 'ok these are a few things that you are entitled to'" (P007). The internet, Facebook, chat rooms and support organisations were frequently used as information sources, with many holding hope for access to new clinical trials. Some mothers reported positive experiences in regard to funding and community assistance, which helped their child access equipment in a timely manner: "I actually really cannot believe the amount of support I've gotten" (P008). This was often the result of strong parent advocacy and perseverance. Gaps in equity of access between metropolitan and rural areas were evident: 'to get a company to come and trial equipment in the house...that takes longer than it does in metropolitan areas' (P006). Participants also explicitly and implicitly voiced determination and resilience, and called for continued efforts to improve information and supportive care services.

\section{DISCUSSION}

This is the first study to provide an in-depth account of the range and nature of costs incurred by families caring for a child with SMA and has identified costs not previously described or under-reported by quantitative studies. Significant financial expenses were combined with high caregiving demands, with implications across all aspects 
of family life, including changes in career choices, and ongoing physical, social and psychological consequences. Desired equipment and activities often could not be afforded, and parents described a constant need to balance costs, redirect resources, 'live without' and spend an enormous amount of time navigating the system. Thus, the results of the present study complement recent quantitative studies that have examined the total costs of care for patients with SMA, ${ }^{68}$ and help to provide a more comprehensive picture of the overall burden of SMA. The high burden of care and psychosocial consequences resonate with recent descriptive studies ${ }^{18-22}$; however, the present study approaches these issues from an economic perspective and highlights the need to reflect such costs in an assessment of the total burden of SMA and for informing economic evaluation of new therapeutic interventions.

Technological advances in supportive care have improved SMA patient survival and quality of life; however, the significant costs of these services and equipment have increased the financial burden on families. Financial support has not kept pace with increasing costs of care, placing greater demands on families to fund these critical services themselves when faced with a lower household income. This is accompanied by the additional costs of high-level care, and its physical and psychosocial consequences. Furthermore, there are ripple effects of chronic childhood illness on other family members' emotional health and lost opportunities. ${ }^{23-26}$ These direct, indirect and opportunity costs are high and the impact on families can be devastating.

Intriguingly, the present and previous studies have reported low levels of engagement with psychological care, ${ }^{6}$ despite the profound impact of SMA for patients and families. ${ }^{1827}$ This may be attributed to a range of individual (eg, stigma, cost, time), health professional (eg, limited awareness, low confidence) and health system (eg, cost, underprioritisation) factors that can prevent or limit timely access to appropriate mental healthcare. ${ }^{26}$ Psychologically informed care and a variety of interventions can prevent or relieve psychological morbidity in parents of young children. ${ }^{28}$ Integrating psychosocial assessment within existing health services has been shown to improve treatment uptake, as well as mental health and parenting outcomes. ${ }^{28}$ Indeed, integrating psychosocial assessment within a clinical setting with which families are already engaged is a key factor distinguishing successful and unsuccessful early mental health interventions. ${ }^{26}$ Providing tailored skills-based training and support to staff also has the potential to overcome barriers to care. Importantly, there are profound health and economic costs associated with not offering mental healthcare. ${ }^{29}$

Despite the economic and emotional burden of SMA, participants voiced resilience and determination, and called for continued efforts to improve information and supportive care services for families. Insufficient information, delays and frustration with access to and utilisation of services resonates generally among carers of children with chronic illness or disability in many settings. ${ }^{30} 31$ Previous studies have suggested clinician knowledge and opinions, as well as regional variations contribute to differences in SMA care. ${ }^{32} 33$ While most carers use the internet and social media to access information, there is a need for education initiatives to bolster discussions between clinicians and carers, and facilitate informed decision-making, greater access to services and resources and ensure equitable care. This has important health service delivery implications, with clearer, more defined care pathways having the potential to decrease the burden on carers as they try to manage the complex care needs of their child as well as the challenges associated with the health system.

Future policy design will also be important in addressing the low labour force participation of carers, including measures to enable greater workforce flexibility, respite care and financial support for families. Equitable access and advocacy for funding assistance and service provision is vital to ensure timely implementation of equipment, and home or vehicle modifications. Promoting wheelchair accessible public spaces, accommodation and transport options will facilitate families in pursuing social and leisure experiences.

While the small sample size and focus on mothers may be a potential limitation of the present study, data saturation was reached by the fifth interview and the cohort was heterogeneous, with a range of socioeconomic backgrounds, ages and functional levels representative of weaker and stronger patients, such that representative conclusions were able to be made. Further studies assessing male relatives, who were not the primary carers in the present cohort, and patients with SMA type 1 will extend understanding. As health systems vary, the generalisability of the results may be another limitation, although this may not be as significant to the carer's perspective of opportunity and psychosocial costs. The findings of this study support the need for routine assessment of the economic impact of SMA in clinical practice and may be used to inform the development of measures or tools to better capture economic burden in this setting. The current clinical translation of nusinersen, with global differences in access and reimbursement and practicalities regarding regular intrathecal administration, will have an additional impact on the range and nature of costs met by families caring for a child with SMA. Including these hidden or uncounted costs is essential in understanding disease impact, providing comprehensive supportive care and informing public policy to efficiently connect families with appropriate services, equipment and resources.

Acknowledgements The authors would like to thank all the families for their commitment and time and who so generously shared their stories. Their valuable experiences and insights were crucial to understanding the costs experienced by patients with SMA and their families.

Contributors All authors contributed to the study design and development of the interview guide. KAC conducted all interviews. MAF, KAC, S-GP, GC, NAK conducted the data analysis and interpretation of the findings. MAF wrote the first draft of the manuscript. All authors contributed to critical review of the findings and revisions to the manuscript. All authors read and approved the final manuscript. 
Funding MAF received grant support from the Motor Neurone Diseases Research Institute of Australia Beryl Bayley MND Postdoctoral Fellowship (152324). NAK is the recipient of a Career Development Fellowship from the National Health and Medical Research Council of Australia (NHMRC APP1049238).

Competing interests MAF has served on the scientific advisory board for Biogen. KAC, S-GP, GC and NAK report no conflicts of interest.

Patient consent Not required.

Ethics approval The study was approved by the Sydney Children's Hospital Human Research Ethics Committee.

Provenance and peer review Not commissioned; externally peer reviewed. Data sharing statement There is no additional unpublished data from this study. Open Access This is an Open Access article distributed in accordance with the Creative Commons Attribution Non Commercial (CC BY-NC 4.0) license, which permits others to distribute, remix, adapt, build upon this work non-commercially, and license their derivative works on different terms, provided the original work is properly cited and the use is non-commercial. See: http://creativecommons.org/ licenses/by-nc/4.0/

(c) Article author(s) (or their employer(s) unless otherwise stated in the text of the article) 2018. All rights reserved. No commercial use is permitted unless otherwise expressly granted.

\section{REFERENCES}

1. Farrar MA, Vucic S, Johnston HM, et al. Pathophysiological insights derived by natural history and motor function of spinal muscular atrophy. J Pediatr 2013;162:155-9.

2. Lemoine TJ, Swoboda KJ, Bratton SL, et al. Spinal muscular atrophy type 1: are proactive respiratory interventions associated with longer survival? Pediatr Crit Care Med 2012;13:e161-5.

3. Oskoui M, Levy G, Garland CJ, et al. The changing natural history of spinal muscular atrophy type 1 . Neurology 2007;69:1931-6.

4. Armstrong EP, Malone DC, Yeh WS, et al. The economic burden of spinal muscular atrophy. $J$ Med Econ 2016;19:822-6.

5. Gillingwater TH. Counting the cost of spinal muscular atrophy. J Med Econ 2016;19:827-8.

6. Klug C, Schreiber-Katz O, Thiele S, et al. Disease burden of spinal muscular atrophy in Germany. Orphanet J Rare Dis 2016;11:58

7. Lewin Group I. Cost of amyotrophic lateral sclerosis, muscular dystrophy, and spinal muscular atrophy in the United States final report prepared for the muscular dystrophy association. Falls Church, VA, 2012.

8. López-Bastida J, Peña-Longobardo LM, Aranda-Reneo I, et al. Social/economic costs and health-related quality of life in patients with spinal muscular atrophy (SMA) in Spain. Orphanet $J$ Rare Dis 2017;12:141.

9. Boardman FK. Experience as knowledge: disability, distillation and (reprogenetic) decision-making. Soc Sci Med 2017;191:186-93.

10. Boardman FK, Young PJ, Warren O, et al. The role of experiential knowledge within attitudes towards genetic carrier screening: A comparison of people with and without experience of spinal muscular atrophy. Health Expect 2018;21:201-11.

11. Boardman F. Experiential knowledge of disability, impairment and illness: The reproductive decisions of families genetically at risk. Health 2014;18:476-92.

12. Farrar MA, Park SB, Vucic $S$, et al. Emerging therapies and challenges in spinal muscular atrophy. Ann Neurol 2017;81:355-68.
13. Finkel RS, Mercuri E, Darras BT, et al. Nusinersen versus sham control in infantile-onset spinal muscular atrophy. $N$ Engl $J$ Med 2017;377:1723-32.

14. Mendell JR, Al-Zaidy S, Shell R, et al. Single-dose genereplacement therapy for spinal muscular atrophy. $N$ Engl $J$ Med 2017;377:1713-22.

15. Mercuri E, Darras BT, Chiriboga CA, et al. Nusinersen versus sham control in later-onset spinal muscular atrophy. $N$ Engl $J$ Med 2018;378:625-35.

16. Farrar MA, Teoh HL, Carey KA, et al. Nusinersen for SMA: expanded access programme. J Neurol Neurosurg Psychiatry 2018 doi: 10.1136/jnnp-2017-317412: [Epub ahead of print]

17. Miles MB, Huberman AM, Saldaña J. Qualitative data analysis: a methods sourcebook. 3rd edn: SAGE Publications, 2014.

18. Qian Y, McGraw S, Henne J, et al. Understanding the experiences and needs of individuals with spinal muscular atrophy and their parents: a qualitative study. BMC Neurol 2015;15:217.

19. Ho HM, Tseng YH, Hsin YM, et al. Living with illness and selftranscendence: the lived experience of patients with spinal muscular atrophy. J Adv Nurs 2016;72.

20. Yang BH, Mu PF, Wang WS. The experiences of families living with the anticipatory loss of a school-age child with spinal muscular atrophy - the parents' perspectives. J Clin Nurs 2016;25:2648-57.

21. Boardman FK, Young PJ, Griffiths FE. Population screening for spinal muscular atrophy: a mixed methods study of the views of affected families. Am J Med Genet A 2017;173:421-34.

22. Boardman FK, Young PJ, Griffiths FE. Impairment experiences, identity and attitudes towards genetic screening: the views of people with spinal muscular atrophy. J Genet Couns 2018;27:69-84.

23. Wakefield CE, McLoone JK, Evans NT, et al. It's more than dollars and cents: the impact of childhood cancer on parents' occupational and financial health. J Psychosoc Oncol 2014;32:602-21.

24. Wakefield CE, Drew D, Ellis SJ, et al. Grandparents of children with cancer: a controlled study of distress, support, and barriers to care. Psychooncology 2014;23:855-61.

25. Read J, Kinali M, Muntoni F, et al. Psychosocial adjustment in siblings of young people with Duchenne muscular dystrophy. Eur J Paediatr Neurol 2010;14:340-8.

26. Kasparian NA, Winlaw DS, Sholler GF. "Congenital heart health": how psychological care can make a difference. Med J Aust 2016;205:104-7.

27. van den Berg B, Fiebig DG, Hall J. Well-being losses due to caregiving. J Health Econ 2014;35:123-31.

28. Yawn BP, Dietrich AJ, Wollan P, et al. TRIPPD: a practice-based network effectiveness study of postpartum depression screening and management. Ann Fam Med 2012;10:320-9.

29. Melnyk BM, Feinstein NF, Alpert-Gillis L, et al. Reducing premature infants' length of stay and improving parents' mental health outcomes with the Creating Opportunities for Parent Empowerment (COPE) neonatal intensive care unit program: a randomized, controlled trial. Pediatrics 2006;118:e1414-27.

30. Greenwood N, Habibi R, Smith R, et al. Barriers to access and minority ethnic carers' satisfaction with social care services in the community: a systematic review of qualitative and quantitative literature. Health Soc Care Community 2015;23:64-78.

31. Cunniff C, Chisholm V, Chouliara Z. Listening to fathers of sons with duchenne muscular dystrophy. New Male Studies 2015;4:5-23.

32. Bladen CL, Thompson R, Jackson JM, et al. Mapping the differences in care for 5,000 spinal muscular atrophy patients, a survey of 24 national registries in North America, Australasia and Europe. $J$ Neurol 2014;261:152-63.

33. Oskoui M, $\mathrm{Ng} \mathrm{P}$, Liben S, et al. Physician driven variation in the care of children with spinal muscular atrophy type 1. Pediatr Pulmonol 2017;52. 